\title{
Application of Green Synthesized MMT/Ag Nanocomposite for Removal of Methylene Blue from Aqueous Solution
}

\author{
Nisha Choudhary ${ }^{1}$, Virendra Kumar Yadav ${ }^{1,2}{ }^{\infty}$, Krishna Kumar Yadav ${ }^{3}{ }^{\circ}$, Abdulaziz Ibrahim Almohana ${ }^{4}$, \\ Sattam Fahad Almojil ${ }^{4}$, Govhindhan Gnanamoorthy ${ }^{5}$ (D), Do-Hyeon Kim ${ }^{6}$, Saiful Islam ${ }^{7}$ (D), Pankaj Kumar ${ }^{8}$ (i) \\ and Byong-Hun Jeon $6, *(\mathbb{B}$
}

check for updates

Citation: Choudhary, N.; Yadav, V.K.; Yadav, K.K.; Almohana, A.I.; Almojil, S.F.; Gnanamoorthy, G.; Kim, D.-H.; Islam, S.; Kumar, P.; Jeon, B.-H. Application of Green Synthesized MMT/Ag Nanocomposite for Removal of Methylene Blue from Aqueous Solution. Water 2021, 13, 3206. https://doi.org/10.3390/ w13223206

Academic Editor: Antonio Zuorro

Received: 29 September 2021 Accepted: 10 November 2021 Published: 12 November 2021

Publisher's Note: MDPI stays neutral with regard to jurisdictional claims in published maps and institutional affiliations.

Copyright: (c) 2021 by the authors. Licensee MDPI, Basel, Switzerland. This article is an open access article distributed under the terms and conditions of the Creative Commons Attribution (CC BY) license (https:/ / creativecommons.org/licenses/by/ $4.0 /)$.
1 Research and Development Centre, YNC ENVIS PVT. LTD., New Delhi 110059, India; nishanaseer03@gmail.com (N.C.); yadava94@gmail.com (V.K.Y.)

2 Department of Microbiology, School of Sciences, P P Savani University, Surat 394125, India

3 Faculty of Science and Technology, Madhyanchal Professional University, Ratibad, Bhopal 462044, India; envirokrishna@gmail.com

4 Department of Civil Engineering, College of Engineering, King Saud University, P.O. Box 800, Riyadh 11421, Saudi Arabia; aalmohanna@ksu.edu.sa (A.I.A.); salmoji@@ksu.edu.sa (S.F.A.)

5 Department of Inorganic Chemistry, Guindy Campus, University of Madras, Chennai 600025, India; gnanadrdo@gmail.com

6 Department of Earth Resources and Environmental Engineering, Hanyang University, Seoul 04763, Korea; kimdohyeon@hanyang.ac.kr

7 Civil Engineering Department, College of Engineering, King Khalid University, Abha 61411, Saudi Arabia; sfakrul@kku.edu.sa

8 Integrated Regional Office, Ministry of Environment, Forest and Climate Change (MoEFCC), Government of India, Saifabad, Hyderabad 500004, India; pankajb434@gmail.com

* Correspondence: bhjeon@hanyang.ac.kr

Abstract: Textile industries are the largest consumer of synthetic dyestuff compounds and consequently, they are the prime contributor of colored organic contaminants to the environment. The dye compounds when released in soil or freshwater resources such as rivers, cause a potential hazard to living beings due to their toxic, allergic and carcinogenic nature. Current conventional treatment methods for removal or degradation of such dyestuff materials from water systems are not sufficient, and therefore, there is an immediate need to find efficient and eco-friendly approaches. In this regard, nanotechnology can offer an effective solution to this problem. In the present work, montmorillonite/silver nanocomposite (MMT/Ag nanocomposite) is developed through green synthesis methods using naturally occurring montmorillonite (MMT) clay and silver nanoparticles. The material was characterized by using a particle size analyzer (PSA), UV/Visible spectroscopy, Fourier transform infrared spectroscopy (FTIR), field emission scanning electron microscope (FE-SEM), energy dispersive X-ray (EDX) spectroscopy and a Brunner-Emmett-Teller (BET) surface area analyzer. The adsorption efficiency of the nanocomposite and per cent removal of methylene blue (MB) was investigated by using a batch system.

Keywords: montmorillonite; silver; nanocomposite; methylene blue; remediation

\section{Introduction}

Human's fascination with "color" has brought a huge revolution to the industrial sector. The textile industry majorly contributes to water pollution by releasing a huge amount of dyestuff as effluent. This untreated or partially treated industrial effluent containing synthetic dye compounds is eventually discharged into water systems, where it causes damage to the aquatic ecosystem [1,2]. Some metal complex-based synthetic dyes are causing severe mutagenic and other health issues even at ppm concentrations [3]. Methylene blue (MB) is one of the most widely used cationic dyes in biological staining and in textile industries because of its faster adsorption on cotton fabric, water solubility 
and economic benefits. However, MB has been reported to cause diarrhea, eye irritation, vomiting, breathing difficulty, nausea and chronic toxicity in humans, mainly in relation to the central nervous system [4,5]. Therefore, the removal of MB dye molecules from aqueous systems has become a crucial requirement. $\mathrm{MB}\left(\mathrm{C}_{16} \mathrm{H}_{18} \mathrm{~N}_{3} \mathrm{SCl}\right)$ is a heterocyclic aromatic compound with $319.85 \mathrm{~g} / \mathrm{mol}$ of molecular weight. $\mathrm{MB}$ is a cationic dye molecule that has a positive charge and its chemical structure is shown in Figure 1.

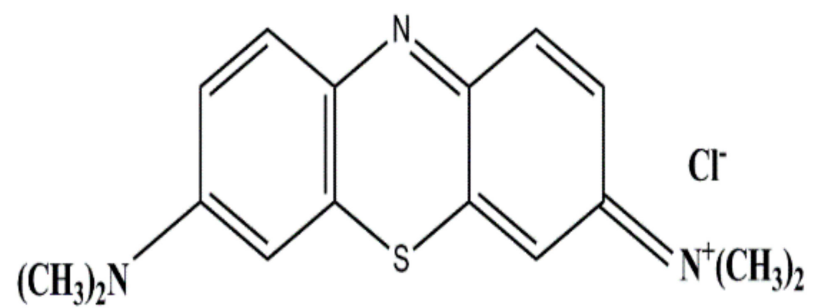

Figure 1. Chemical structure: MB chloride salt.

Various physicochemical and biological treatment methods are available for the removal of MB dye molecules from the water system [6,7]. Further, various conventional methods such as coagulation, flocculation [8], oxidation/ozonation [9], membrane-based separation [10] have been used to separate dye molecules from wastewater [11]. However, there are some limitations with these methods such as high cost, toxic intermediate production, and lower efficiency. Therefore, adsorption techniques are being used by industries because of their low cost and easy handling [12-14].

Numerous adsorbents (natural and engineered) have been studied by various researchers for the removal of dye molecules such as activated carbon [15,16], zeolite [17], tourmaline [18], black phosphorous nanosheet [19], waste materials [20], dead biomass [21], natural clay and clay minerals [22,23] and agricultural waste materials [24]. Recently, nanotechnology-driven materials such as clay/metal nanocomposites are being explored for their potential as efficient adsorbents, where metal nanoparticles act as fillers and clay provides support for their synthesis. Clay is an abundantly available, natural and low-cost material with excellent cation exchange efficiency due to its high surface area, mechanical stability, swelling properties and high cation exchange capacity (CEC) [25]. Montmorillonite (MMT) is one such clay mineral that has been studied for its ability to adsorb different types of dye compounds [26]. Silver nanoparticles are used for catalytic degradation of textile dyes [27].

Some previous studies have reported the synthesis of MMT clay and silver nanocomposite by the chemical reduction method [28], $\gamma$-irradiation technique [29], and green methods using plant extracts of medicinal plants [30-32] and fruit waste [33]. These studies have focused on the antimicrobial property of the nanocomposite. In the present study, we have developed montmorillonite clay/silver (MMT/Ag) nanocomposite as an adsorbent material for the removal of MB dye from its liquid solution, keeping in mind that clay has a high cationic exchange capacity, high absorption capacity and silver nanoparticles are also known to have good catalytic efficiency [34]. Besides, this is the first time we are reporting the use of a weed plant, "sida acuta" extract for the synthesis of an MMT/Ag nanocomposite where MMT clay is used as a matrix and silver nanoparticles as nanofillers. Sida acuta Burm. f., also known as broom weed, is a perennial undershrub of the Malvaceae family. Although, the weed plant has its native roots in Central America, it is also widely distributed in pan-tropical regions of the world including India. S. acuta is used for the treatment of diseases related to the liver, blood, and the urinary and nervous systems [35]. This plant contains bioactive compounds, thus it has numerous pharmacological activities such as anti-ulcer, analgesic, antipyretic, antiviral, anti-plasmodial, anticancer, antimicrobial and anti-inflammatory properties [36]. The use of the extract from the weed leaves is a rapid, economic and environmentally-friendly method for nanomaterial synthesis.

The phytochemicals and bioactive compounds in the aqueous leaf extract of $S$. acuta act as a reducing agent for silver salt and result in the formation of silver nanoparticles 
in the lamellar space of MMT clay [32]. The clay acts as a matrix in the composite, which provides support and also prevents the agglomeration of silver nanoparticles during the synthesis process. The developed nanocomposite and raw MMT clay were characterized for their morphology and structural information. The PSA provided information related to the particle size of nanocomposite material whereas FTIR analysis was carried out to observe the functional groups in the sample. FE-SEM analysis was done to study the surface features, EDX for elemental analysis, and BET surface area analysis was conducted to evaluate the specific surface area. Finally, the adsorption potential of the developed nanocomposite was studied by conducting batch adsorption experiments for the removal of MB dye from an aqueous solution.

\section{Materials and Methods}

\subsection{Reagents and Materials}

Silver nitrate $\left(\mathrm{AgNO}_{3}\right.$, with $99.00 \%$ purity and montmorillonite (MMT) clay used for the study were purchased from Merck. Sida acuta leaves were collected from the Gandhinagar region, Gujarat, India. The solutions were prepared using distilled water (DW).

\subsection{Synthesis of MMT/Ag Nanocomposite}

Freshly collected Sida acuta leaves were washed by thorough rinsing with DW to ensure complete removal of unwanted particles and were allowed to dry in the shade. Then, $10 \mathrm{gm}$ of dry S. acuta leaves were boiled in $100 \mathrm{~mL}$ of DW at $100{ }^{\circ} \mathrm{C}$ for $5 \mathrm{~min}$ as shown in Figure 2.

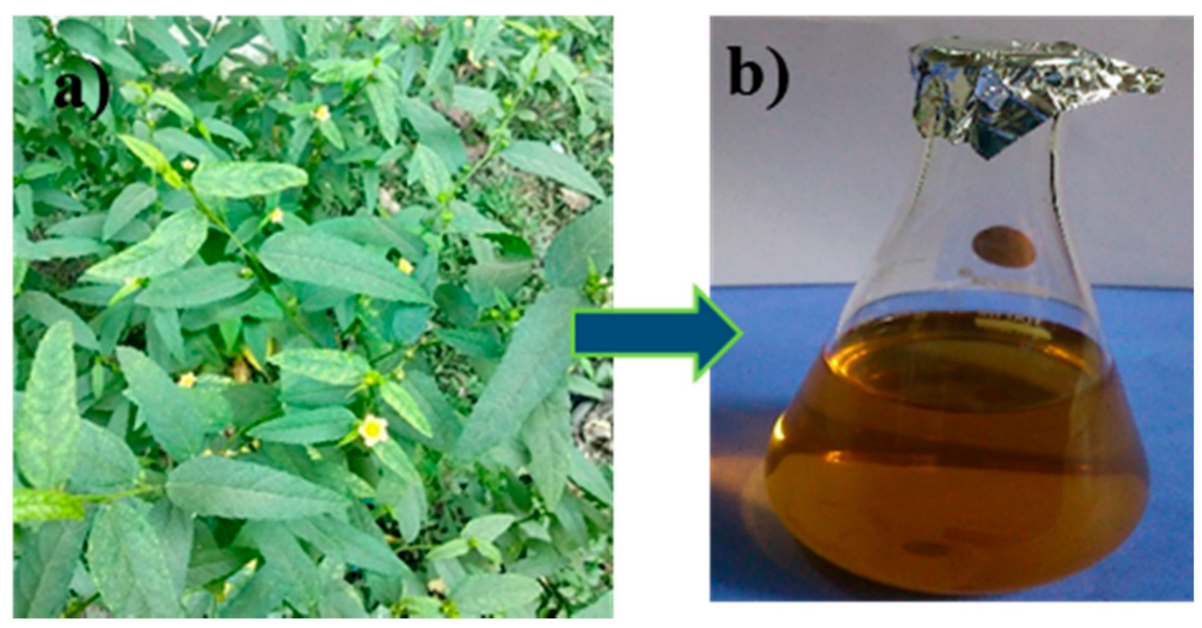

Figure 2. Sida acuta: (a) Plant and (b) Leaf extract.

The leaf extract was allowed to cool to room temperature and then filtered to remove pigments and other insoluble fractions. This fresh extract was used for nanocomposite synthesis. For nanocomposite preparation, $10 \mathrm{gm}$ of MMT clay was dried in a hot air oven at $50{ }^{\circ} \mathrm{C}$ for $30 \mathrm{~min}$. Figure 3 presents the synthesis procedure for the development of MMT/Ag nanocomposite. 


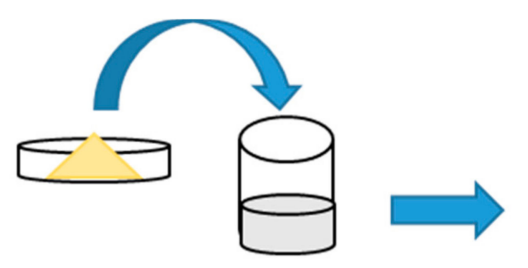

MMT clay $(5 \mathrm{gm})+0.01 \mathrm{M}$ $\mathrm{AgNO}_{3}$ solution $(200 \mathrm{~mL})$

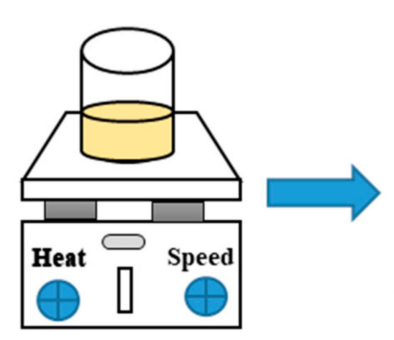

Magnetic stirring (120 rpm; room temp.)

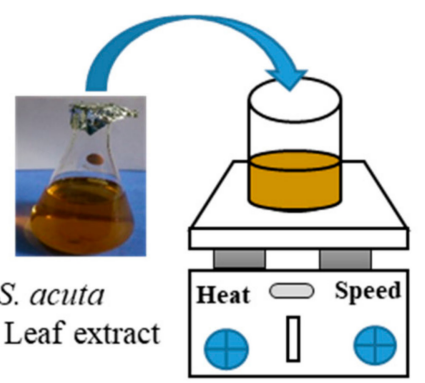

$20 \mathrm{~mL}$ Extract added to MMT$\mathrm{AgNO}_{3}$ solution; room temp.

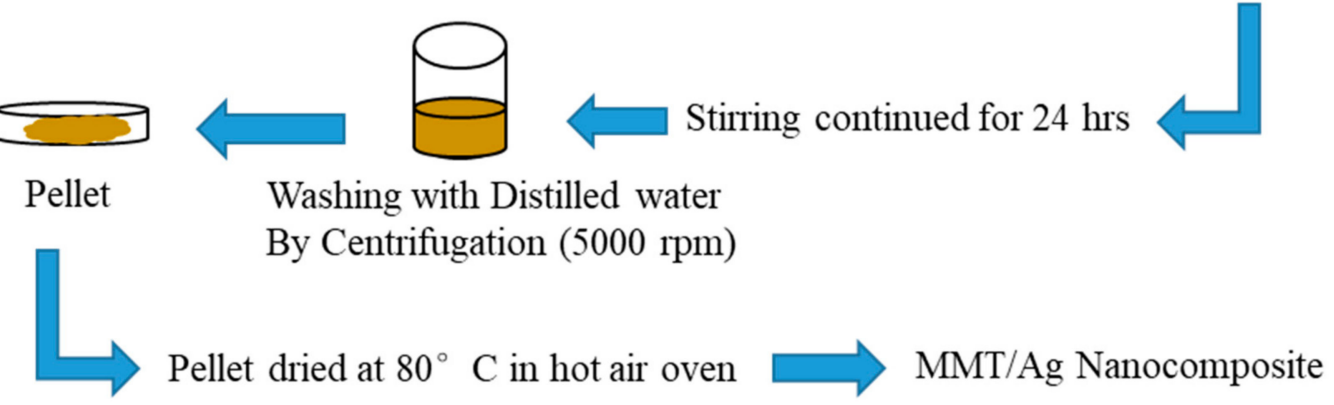

Figure 3. Synthesis process of MMT/Ag nanocomposite.

\subsection{Batch Adsorption Experiments}

Batch experiments were used to study the effects of experimental parameters such as different concentrations of MB (25, 50100 and $200 \mathrm{ppm})$, contact time, adsorbent dosage $(25,50,100 \mathrm{mg}$ in $50 \mathrm{~mL}$ of MB solution) and the initial dye concentration on the absorption of the dye by the nanocomposite. For these experiments, $250 \mathrm{~mL}$ conical flasks with $50 \mathrm{~mL}$ of dye solution were used. To determine the adsorption capacity of MMT/Ag nanocomposite, $50 \mathrm{~mL}$ of MB solution with varying concentrations ( $25 \mathrm{ppm}, 50 \mathrm{ppm}, 100 \mathrm{ppm}$, and $200 \mathrm{ppm}$ ) was prepared. An assessment of different adsorbent doses was conducted with $50 \mathrm{~mL}$ of $50 \mathrm{ppm}$ dye solution and $50 \mathrm{mg}$ of MMT/Ag nanocomposite was added to the MB solutions. The mixtures were agitated mechanically in a rotary shaker at $150 \mathrm{rpm}$ for $30 \mathrm{~min}$. After a $5 \mathrm{~min}$ interval, aliquots of $3 \mathrm{~mL}$ reaction mixture were centrifuged at $5000 \mathrm{rpm}$ for $5 \mathrm{~min}$. Further, the supernatant solution was examined for the remaining MB concentration by using a UV spectrophotometer $\left(\lambda_{\max }=665 \mathrm{~nm}\right.$ ). The per cent removal of dye and the adsorption capacity of adsorbent at any time $\left(\mathrm{q}_{\mathrm{t}}\right)$ and at equilibrium $\left(\mathrm{q}_{\mathrm{e}}\right)$ were analyzed using the following equations.

$$
\begin{gathered}
\% \text { Removal }=\frac{C_{0}-C_{t}}{C_{0}} \times 100 \\
\mathrm{q}_{\mathrm{t}}(\mathrm{mg} \mid \mathrm{g})=\frac{\left(C_{0}-C_{t}\right) \mathrm{V}}{M} \\
\mathrm{q}_{\mathrm{e}}(\mathrm{mg} \mid \mathrm{g})=\frac{\left(C_{0}-C_{e}\right) \mathrm{V}}{M}
\end{gathered}
$$

where:

\footnotetext{
$C_{0}=$ initial $\mathrm{MB}$ concentration in $\mathrm{mg} / \mathrm{L}$;

$C_{t}=\mathrm{MB}$ concentration at time $t$, in $\mathrm{mg} / \mathrm{L}$;

$\mathrm{Ce}=\mathrm{MB}$ concentration at equilibrium, in $\mathrm{mg} / \mathrm{L}$

$V=$ volume of $\mathrm{MB}$ solution in liters;

$M=$ mass of adsorbent material in grams (g).
} 


\subsection{Characterization Techniques}

Both MMT clay and MMT/Ag nanocomposite were analyzed by FTIR for the identification of functional groups, for which $2 \mathrm{mg}$ powder samples were mixed with $98 \mathrm{mg}$ of $\mathrm{KBr}$ to obtain a solid pellet. The analysis was done by using the Perkin Elmer "Spectrum 6500" (USA). The measurement was done in the band region of $400-4000 \mathrm{~cm}^{-1}$, with a resolution of $1 \mathrm{~nm}$. The particle size distribution of both MMT and MMT/Ag nanocomposite was analyzed by a particle size analyzer, for which liquid formulations was prepared by dispersing 1-2 $\mathrm{mg}$ powders in double-distilled water (ddw) and sonicating for $10 \mathrm{~min}$ in an ultrasonicator (Sonar, $40 \mathrm{Khz}$, Gujarat, India). The sonicated dispersed samples were divided into two portions, one portion was used for the PSA measurement, which was done by the Malvern Zetasizer, Z-90 (Malvern Instruments Ltd, Malvern, UK) at room temperature (RT), while the second portion of the dispersed sample was used for the UV-Vis measurement in the range of 200-700 nm, using a 2060+ Analytical double-beam spectrophotometer (Analytik Jena Japan Co., Ltd., Yokohama Kanagawa, Japan). For FE-SEM analysis of the powder samples, a pinch of the samples was spread on a carbon tape, which was fixed on the aluminum stub. Both the samples were subjected to gold sputtering. FESEM analysis revealed the morphological properties of the samples, and the measurement was done by using the Nova NanoSEM 450 (FEI Company. Hillsboro, OR, USA), while the elemental analysis of the samples was done by using the attached Bruker-made EDX analyzer. A BET analyzer was used for the measurement of the surface area and the pore size of both the powder samples NOVA 1200e (Quanta Chrome Instruments, Vernon Hills, IL, USA).

\section{Results and Discussions}

\subsection{PSA for Particle Size Distribution}

The particle size distribution of both MMT and MMT/Ag nanocomposite was analyzed by a particle size analyzer, for which liquid formulations were prepared by dispersing 1-2 $\mathrm{mg}$ powders into the DW and sonicating for $10 \mathrm{~min}$ in an ultrasonicator (Sonar, $40 \mathrm{KHz}$ ). The PSA graph of both the particles exhibits two types of species, i.e., it is a bimodal graph as shown in Figure 4. The majority of the MMT particles are below $1000 \mathrm{~nm}$, while some of the particles fall in the size range of $3000-4000 \mathrm{~nm}$. The average size of the MMT particle is $341.3 \mathrm{~nm}(\mathrm{dm})$ and the zeta potential value is $-37.13 \mathrm{mv}$.

In the case of MMT / Ag nanocomposite, the majority of the particles also vary in size from $100 \mathrm{~nm}$ to $1000 \mathrm{~nm}$, while the size of the particles ranges from 4500 to $6000 \mathrm{~nm}$ in the total population. The average size of the MMT/Ag nanocomposite particles is $366.2 \mathrm{~nm}$ and the zeta potential is $-16.49 \mathrm{mv}$.

So, based on the PSA, it is clear that the size of the MMT/Ag nanocomposite increased slightly, i.e., $15-20 \mathrm{~nm}$, as the silver nanoparticles were deposited on the surface of the clay, which is also evidenced by the microscopic analysis and XRD. The zeta potential was decreased in the case of the nanocomposite, which may indicate the instability of the samples in the solution as compared to clay, as the deposition or loose attachment of the silver nanoparticles on the surface of the clay might have made them unstable in the distilled water. Gashti et al. also reported that the presence of silver nanoparticles on the surface of clay (kaolin) decreased the thermal stability of the material due to proton delocalization of hydroxyl groups in the nanocomposite [37]. 

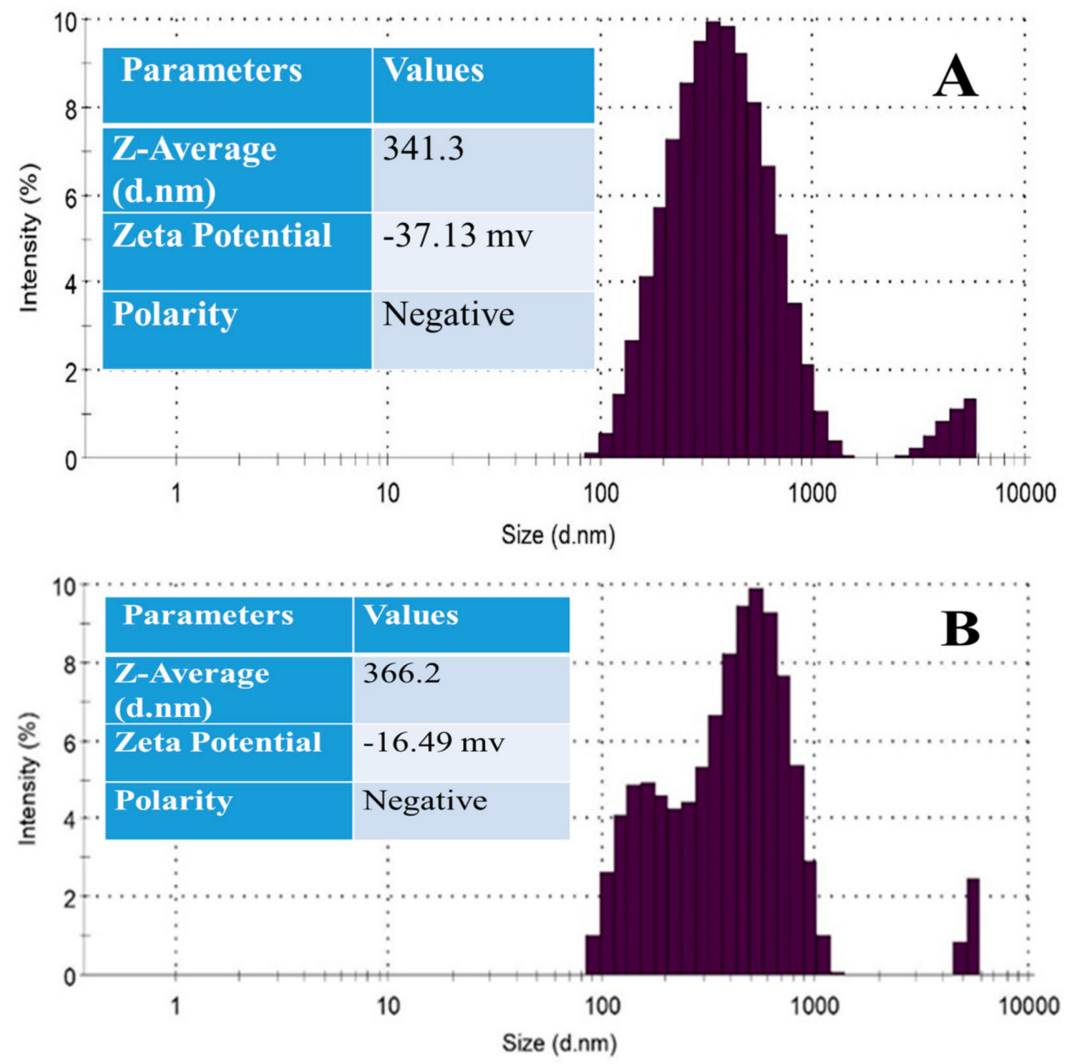

Figure 4. PSA graph of (A) MMT clay and (B) MMT/Ag nanocomposite.

\subsection{UV-Visible Spectroscopy Analysis}

Light absorption by the molecules in the UV or near UV region of the electromagnetic spectrum results in electronic transitions from the ground state to a state of higher energy. This happens because of a high degree of conjugation of the molecules. The UV-Vis spectra for MMT clay and MMT/Ag nanocomposite are shown in Figure 5 with peaks ranging from $200-400 \mathrm{~nm}$.

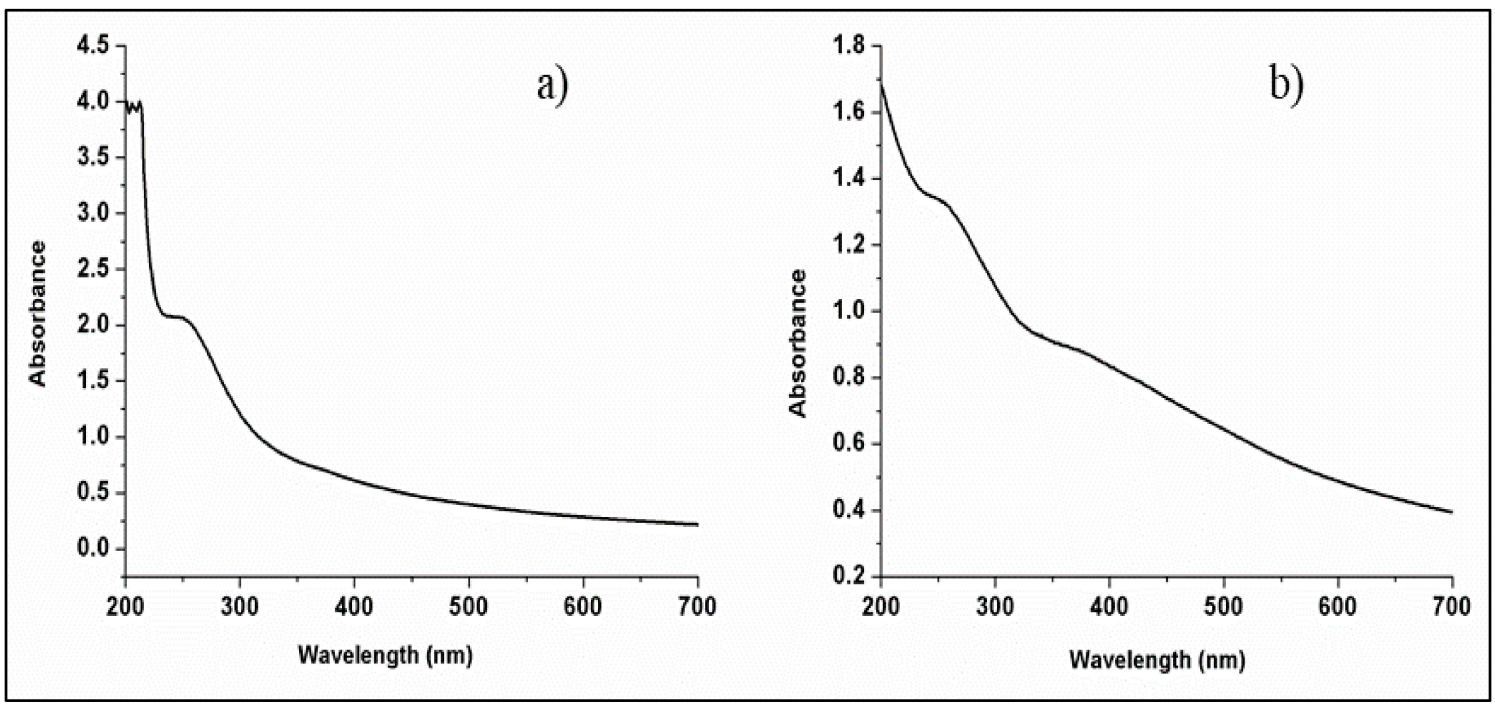

Figure 5. UV-Vis spectra: (a) MMT clay and (b) MMT/Ag nanocomposite.

In the MMT clay sample, the characteristic bands are present in the ultraviolet region (200-400 nm), i.e., at $210 \mathrm{~nm}, 214 \mathrm{~nm}$ and $250 \mathrm{~nm}$. Bands at $210 \mathrm{~nm}$ and $214 \mathrm{~nm}$ point to the 
existence of exchange sites and iron valency in the lattice. These absorption bands display the charge translocation of oxo-to-iron (III) [38]. Also, the EDX analysis of the clay confirms the presence of iron in its elemental composition. The absorption peak at $250 \mathrm{~nm}$ is due to $\pi$-to- $\pi^{*}$ electronic transition of the functional group $\mathrm{Si}=\mathrm{O}$. The vibrational frequencies of group $\mathrm{Si}=\mathrm{O}$ were also detected in the FTIR spectra of MMT clay. A similar study regarding UV spectroscopic analysis of MMT clay has been reported by Wanyika et al. [39]. The absorption spectrum of MMT/Ag nanocomposite shows a low-intensity band at $365 \mathrm{~nm}$, which confirms the presence of silver nanoparticles in the matrix of MMT clay.

\subsection{FTIR Analysis}

The FT-IR analysis showed that spectra (Figure 6) for MMT and MMT/Ag nanocomposite were quite similar with a slight shift in the band's position and intensity. In both samples, $\mathrm{Si}-\mathrm{O}$ and $\mathrm{Al}-\mathrm{OH}$ were the main functional groups detected in the range of $1000 \mathrm{~cm}^{-1}$ and $500 \mathrm{~cm}^{-1}$.

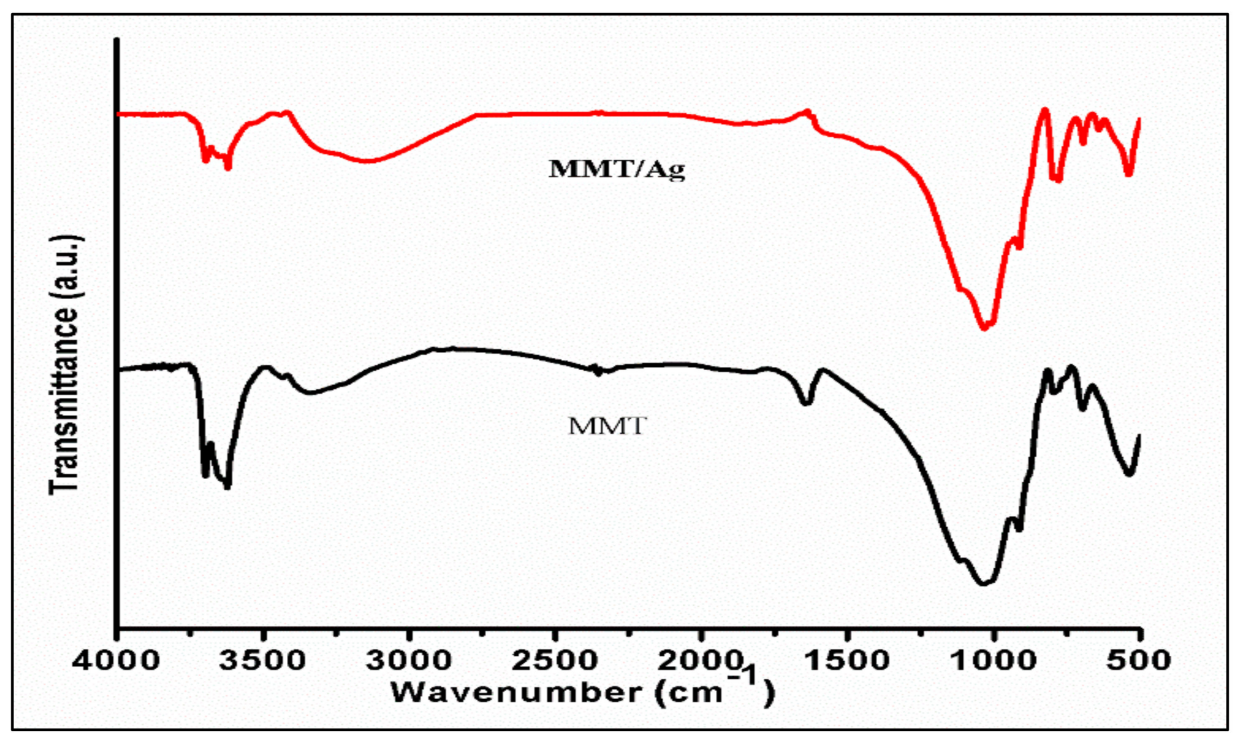

Figure 6. FTIR spectra of MMT and MMT/Ag nanocomposite.

The absorption peak at $528 \mathrm{~cm}^{-1}$ and $790 \mathrm{~cm}^{-1}$ is because of the bending vibration of the Al-O-Si bond and the $\mathrm{Fe}^{3+}-\mathrm{OH}-\mathrm{Mg}$ stretch, respectively. Bands at $1130 \mathrm{~cm}^{-1}$, and $1048 \mathrm{~cm}^{-1}$ were attributed to Si-O stretching vibrations. IR peaks at $3626 \mathrm{~cm}^{-1}$ and $918 \mathrm{~cm}^{-1}$ were ascribed to the Al-Al-OH group of MMT clay [40], while bands at $3710 \mathrm{~cm}^{-1}$, $3448 \mathrm{~cm}^{-1}$ and $1675 \mathrm{~cm}^{-1}$ were assigned to the $\mathrm{O}-\mathrm{H}$ functional group, which is due to the existence of water molecules between the layers of MMT. Similar FTIR spectral results for MMT were found by Wanyika et al. The IR spectrum for the MMT/Ag nanocomposite was similar to that of MMT with peaks or bands at the same location but with altered intensities. For instance, the IR band at $918 \mathrm{~cm}^{-1}$ moved slightly to $914 \mathrm{~cm}^{-1}$ with an enhanced intensity, which indicates an increase in the mass of the molecules due to silver nanoparticles-MMT clay interaction. The MMT/Ag nanocomposite spectra showed a new absorption band near $3150 \mathrm{~cm}^{-1}$, which is an indication of the interaction between silver nanoparticles and the O-H functional group in the MMT layers $[29,41]$.

\subsection{FESEM, TEM and EDX Analysis}

The analysis of surface structures and elemental composition of MMT clay and MMT/Ag nanocomposite was done using FESEM and EDX (Figure 7). The results suggest that the nanocomposite has a flaky and layered structure that contains silicon, aluminum and silver as the principal constituents. 


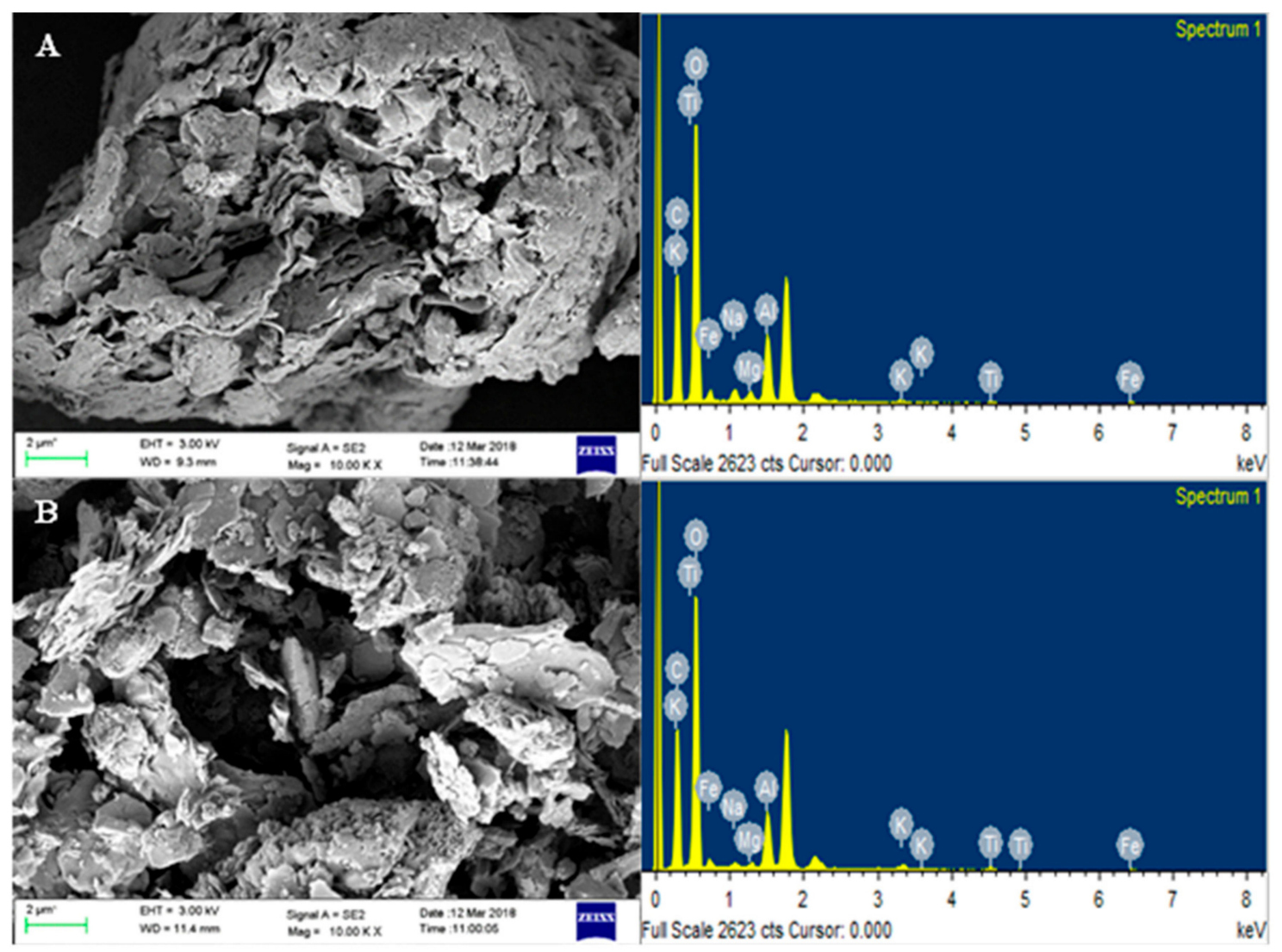

Figure 7. FESEM images and EDX spectrum of (A) MMT clay and (B) MMT/Ag nanocomposite.

The FESEM images of MMT/Ag nanocomposite shows the presence of silver nanoparticles on large flakes of MMT clay, confirming the interaction between the two. Also, the interaction between MMT and silver nanoparticles in the nanocomposite has already been proven by the FTIR results. The elemental composition of the nanocomposite obtained by EDX showed that it contains $\mathrm{Si}(31.55 \%), \mathrm{Al}(6.02 \%), \mathrm{Fe}(8.86 \%)$, and $\mathrm{Ag}$ (1.38\%). Hence, microscopic analysis outcomes suggest that the nanocomposite is a heterogeneous composite containing flakes of MMT and silver nanoparticles.

\subsection{BET Surface Area Analysis}

The specific surface area and porosity of MMT clay and MMT/Ag nanocomposite were analyzed by using the BET analyzer model no. NOVA-1200e (Quanta Chrome Instruments). Surface area analysis by BET involves the physisorption of gas (nitrogen) onto the sample surface with weak van der Waal force. The Barrett-Joyner-Halenda (BJH) method was used for the evaluation of pore volume and pore diameter. The results are shown in Table 1. The surface area of MMT/Ag nanocomposite was found to be higher than raw MMT clay. The nanocomposite specific surface area was found to be $82.663 \mathrm{~m}^{2} / \mathrm{g}$ with a pore volume and pore diameter of $0.127 \mathrm{cc} / \mathrm{g}$ and $4.136 \mathrm{~nm}$, respectively. Smaller pore size and higher specific surface area are characteristic features of an efficient and highly capable adsorbent [42].

Table 1. Surface area of MMT and MMT/Ag nanocomposite.

\begin{tabular}{cccc}
\hline Material & $\begin{array}{c}\text { Surface Area } \\
\left(\mathbf{m}^{2} / \mathbf{g}\right)\end{array}$ & $\begin{array}{c}\text { Pore Volume } \\
(\mathbf{c c} / \mathbf{g})\end{array}$ & $\begin{array}{c}\text { Average Pore } \\
\text { Diameter (nm) }\end{array}$ \\
\hline Montmorillonite Clay (Raw) & 77.234 & 0.116 & 3.782 \\
\hline MMT/Ag nanocomposite & 82.663 & 0.127 & 4.136 \\
\hline
\end{tabular}




\subsection{Adsorption Results of MB Using MMT/Ag Nanocomposite}

The adsorption system was evaluated by examining the results of various experimental parameters such as the effect of contact time, initial MB concentration and nanoadsorbent dose.

\subsubsection{Effect of Contact Time}

The removal of MB from aqueous solution occurred either via a physisorption or chemosorption process. During $30 \mathrm{~min}$ of contact time, the amount of MB adsorbed onto the nanocomposite was found to increase with time up to $20 \mathrm{~min}$, and then it attained equilibrium. A quick decrease in the $\mathrm{MB}$ concentration during the initial 5 min shows strong contact between the cationic dye $\mathrm{MB}$ and the negative charge-carrying nanocomposite material. After $5 \mathrm{~min}$, the $\mathrm{MB}$ adsorption increased gradually up to $20 \mathrm{~min}$. The per cent removal of four different concentrations of $\mathrm{MB}$ using a fixed amount of raw clay and adsorbent, up to $30 \mathrm{~min}$ of contact time is shown in Figure 8. The figure shows that MB removal efficiency (for all four concentrations) increased with contact time whereas the per cent removal of $\mathrm{MB}$ decreased with the increase in $\mathrm{MB}$ concentration. After $30 \mathrm{~min}$ of contact time, the MMT/Ag nanocomposite showed MB removal of $99.90 \%$ for $25 \mathrm{ppm}$, $96.50 \%$ for $50 \mathrm{ppm}, 89 \%$ for $100 \mathrm{ppm}$ and $81.14 \%$ for $200 \mathrm{ppm}$. Similar results were reported by [43] for MB dye adsorption by montmorillonite clay.

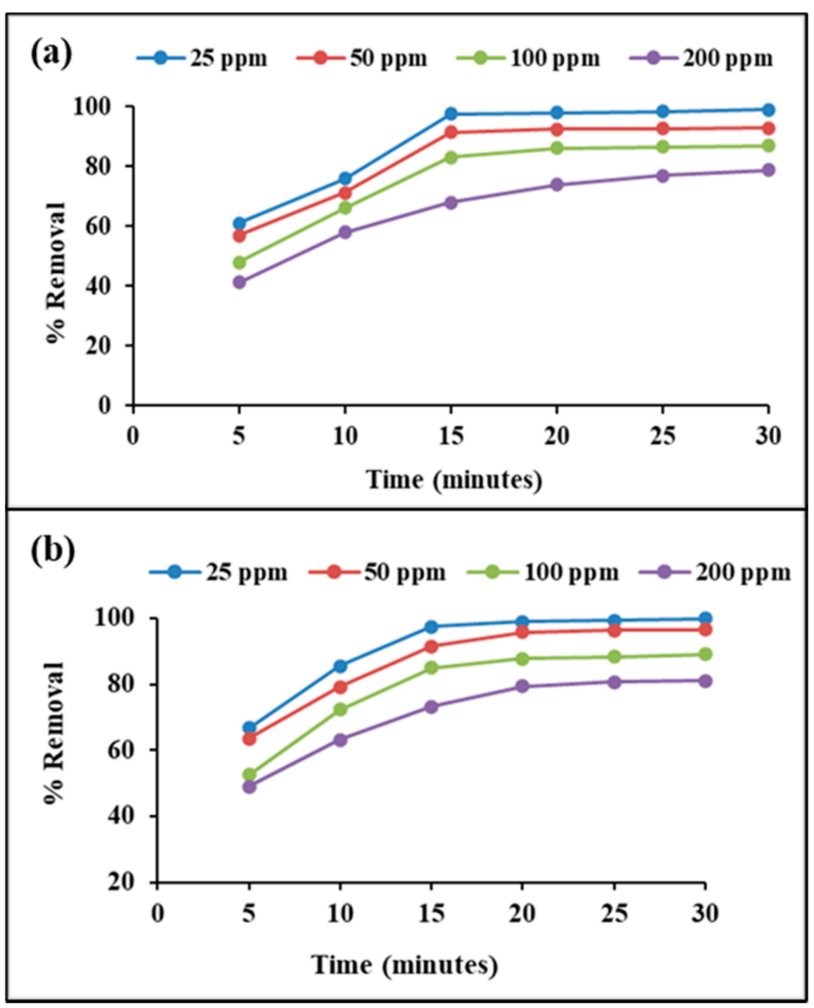

Figure 8. Removal percentage of MB using (a) MMT clay and (b) MMT/Ag nanocomposite.

\subsubsection{Effect of Initial MB Concentration}

Figure 9 shows the effect of increasing the initial MB concentration on the adsorption efficiency of the raw MMT clay and nanocomposite. The removal efficiency of both materials decreased with increasing MB concentration. The reason could be the unavailability of sufficient active sites on the nanocomposite surface for binding with MB ions. Similar observations were reported by [44] for MB adsorption on red clay. 


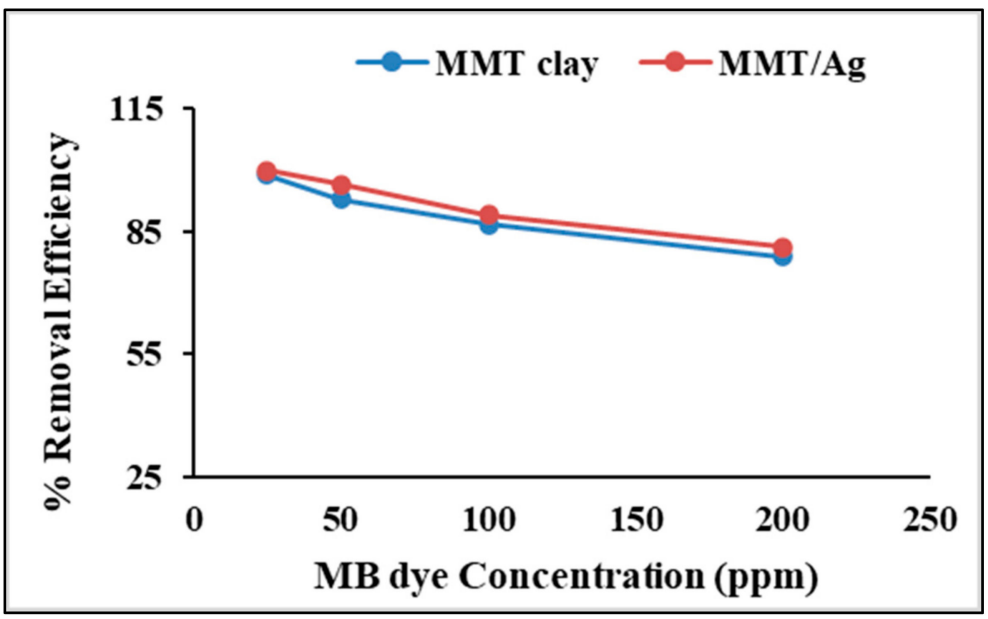

Figure 9. Effect of initial MB concentration on adsorption by raw MMT clay and MMT/Ag nanocomposite.

\subsubsection{Effect of Adsorbent Dose}

To identify the optimum adsorbent dose, the effects of adsorbent dosage was studied with regard to the amount of $\mathrm{MB}$ concentration. In general, increasing the adsorbent dose increases the removal efficiency. Figure 10 shows an increase in the removal efficiency of adsorbents, which is due to the easy and excessive availability of adsorption sites at the nanocomposite surfaces. Increases in the removal efficiency slowed down after $50 \mathrm{mg}$, which suggested that $50 \mathrm{mg}$ is the optimum nanocomposite dose for adsorption of $100 \mathrm{ppm}$ $\mathrm{MB}$ dye from an aqueous solution. The obtained outcome is in good agreement with the results reported by [45].

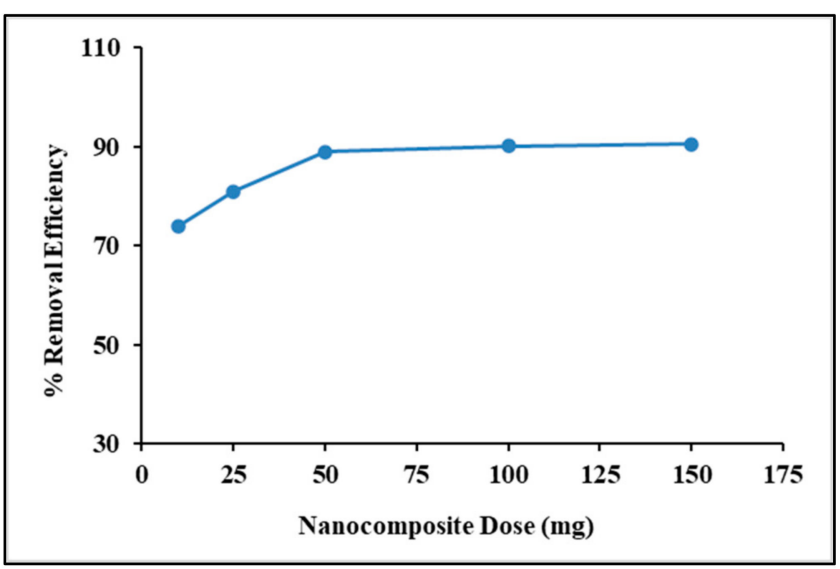

Figure 10. Effect of adsorbent doses on MB removal efficiency.

\subsubsection{Effect of Contact Time on Adsorption Capacity of Nanocomposite}

The variations detected in MB adsorption on MMT clay (raw) and MMT/Ag nanocomposite as a function of contact time are shown in Figure 11a-d. The figure shows that the maximum MB adsorption occurred during the initial $15 \mathrm{~min}$. Afterwards, it increased gradually and almost reached equilibrium within $30 \mathrm{~min}$ of the initial contact. The faster adsorption rate in the initial time period is because vacant and available sites on the negativelycharged adsorbent surface result in faster adsorption of negative charge-carrying MB dye from the aqueous solution at neutral $\mathrm{pH}[46,47]$. Further, the decreased adsorption rate is due to a lack of available active sites resulting from MB monolayer formation on the adsorbent surface. Similar results were also reported by Vutskits et al. [5] for MB adsorption by activated carbon. The adsorption capacity of raw MMT clay ranged from $13 \mathrm{mg} / \mathrm{g}$ to $151.68 \mathrm{mg} / \mathrm{g}$ and MMT/Ag nanocomposite ranged from 14.32 to $156.22 \mathrm{mg} / \mathrm{g}$ against adsorption of MB dye [48]. 


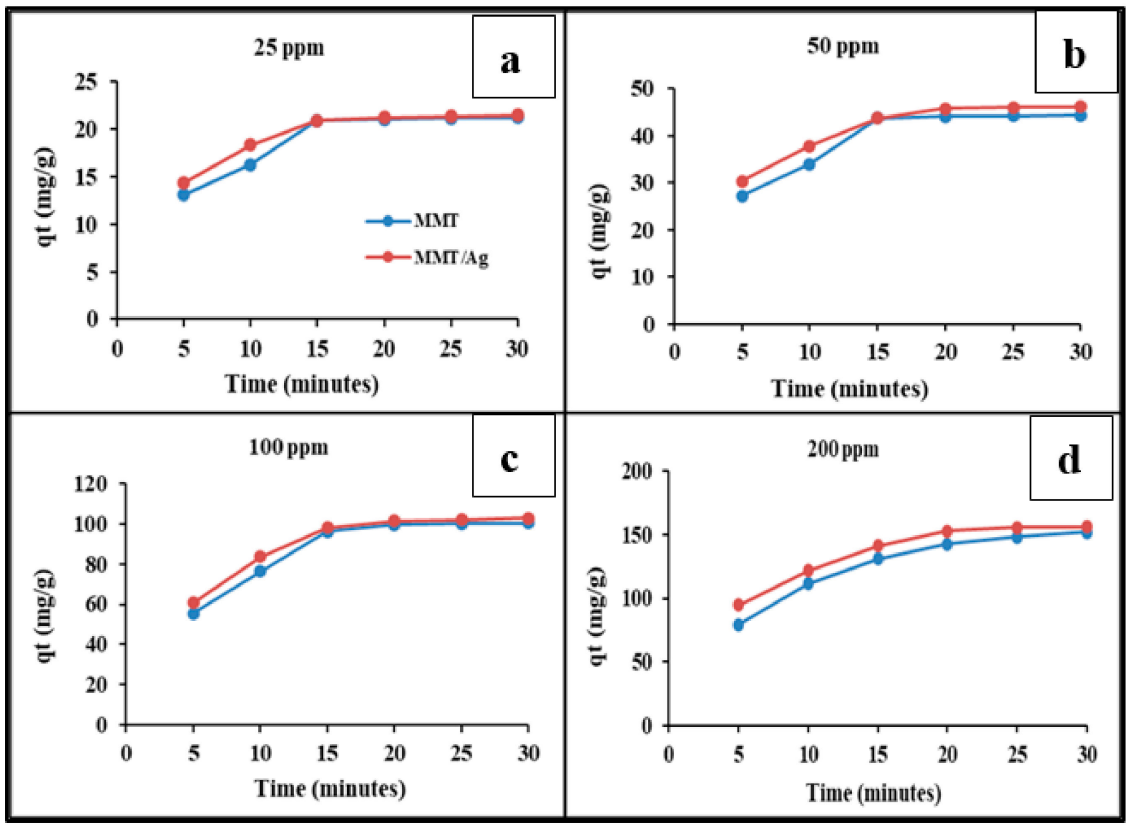

Figure 11. Effect of the contact time on adsorption capacity of raw MMT clay and MMT/Ag nanocomposite (a) 25 ppm, (b) 50 ppm (c) 100 ppm and (d) 200 ppm of dyes.

\section{Conclusions}

The outcomes of the present research study show that MMT/Ag nanocomposite was successfully synthesized using a weed plant extract and effectively used as an adsorbent for the removal of cationic dyes from an aqueous medium. The FTIR results showed the interaction between the clay and silver nanoparticles and the FESEM study revealed the layered, sheet-like morphology of MMT/Ag nanocomposite. The MB adsorption study showed that both raw MMT and MMT/Ag nanocomposite have potential for the removal of MB dye and the difference in their adsorption efficiency was found to be very small. This might be due to the low silver content in the developed nanocomposite material. Further research should be conducted with different clay: Ag ratios in order to evaluate the adsorption capacity of clay/Ag nanocomposite against the adsorption of MB dye. Silver-based clay nanocomposites are well-known antimicrobial agents. More research on this material could provide a solution for the removal of microbial and organic pollutants from wastewater.

Author Contributions: Conceptualization, A.I.A., V.K.Y., S.F.A., G.G. and A.I.A.; Data curation, N.C., A.I.A., S.I. and S.F.A.; Methodology, N.C., G.G., D.-H.K. and P.K.; Validation, K.K.Y., S.I., N.C., B.-H.J. and D.-H.K.; Formal analysis, V.K.Y. and A.I.A.; Resources, B.-H.J. and K.K.Y.; Writing-original draft preparation, N.C.; Writing-review and editing, V.K.Y., K.K.Y., N.C., S.F.A., A.I.A. and S.I.; Supervision, V.K.Y., K.KY. and B.-H.J.; Project administration, A.I.A. and B.-H.J.; Funding acquisition, B.-H.J., S.F.A. and A.I.A.; Investigation, V.K.Y., B.-H.J. and P.K., S.I.; Software, G.G., K.K.Y., P.K. and D.-H.K.; Visualization, P.K., V.K.Y. and D.-H.K. All authors have read and agreed to the published version of the manuscript.

Funding: The authors would like to acknowledge the support of the Researchers Supporting Project number (RSP-2021/303), King Saud University, Riyadh, Saudi Arabia. This study was supported by grants from the Korea Institute of Energy Technology Evaluation and Planning (KETEP) funded by the Ministry of Trade, Industry \& Energy (MOTIE) of the South Korean Government (No. 20206410100040).

Conflicts of Interest: There is no conflict of interest regarding the publication of this paper. 


\section{References}

1. Lellis, B.; Fávaro-Polonio, C.Z.; Pamphile, J.A.; Polonio, J.C. Effects of textile dyes on health and the environment and bioremediation potential of living organisms. Biotechnol. Res. Innov. 2019, 3, 275-290. [CrossRef]

2. Berradi, M.; Hsissou, R.; Khudhair, M.; Assouag, M.; Cherkaoui, O.; El Bachiri, A.; El Harfi, A. Textile finishing dyes and their impact on aquatic environs. Heliyon 2019, 5, e02711. [CrossRef]

3. Velusamy, S.; Roy, A.; Sundaram, S.; Kumar Mallick, T. A Review on Heavy Metal Ions and Containing Dyes Removal through Graphene Oxide-Based Adsorption Strategies for Textile Wastewater Treatment. Chem. Record. 2021, 21, 1570-1610. [CrossRef] [PubMed]

4. Bayomie, O.S.; Kandeel, H.; Shoeib, T.; Yang, H.; Youssef, N.; El-Sayed, M.M. Novel approach for effective removal of methylene blue dye from water using fava bean peel waste. Sci. Rep. 2020, 10, 7824. [CrossRef]

5. Vutskits, L.; Briner, A.; Klauser, P.; Gascon, E.; Dayer, A.G.; Kiss, J.Z.; Muller, D.; Licker, M.J.; Morel, D.R. Adverse effects of methylene blue on the central nervous system. J. Am. Soc. Anesthesiol. 2008, 108, 684-692. [CrossRef]

6. Donkadokula, N.Y.; Kola, A.K.; Naz, I.; Saroj, D. A review on advanced physico-chemical and biological textile dye wastewater treatment techniques. Rev. Environ. Sci. Bio. Technol. 2020, 19, 543-560. [CrossRef]

7. Zeng, Y.; Zhang, F.; Wang, M. Removal of methylene blue and mechanism on magnetic $\gamma-\mathrm{Fe}_{2} \mathrm{O}_{3} / \mathrm{SiO}_{2}$ nanocomposite from aqueous solution. Water Resour. Ind. 2016, 15, 1-13.

8. Rahbar, M.S.; Alipour, E.; Sedighi, R.E. Color removal from industrial wastewater with a novel coagulant flocculant formulation. Int. J. Environ. Sci. Technol. 2006, 3, 79-88. [CrossRef]

9. Malik, P.K.; Saha, S.K. Oxidation of direct dyes with hydrogen peroxide using ferrous ion as catalyst. Sep. Purif. Technol. 2003, 31, 241-250. [CrossRef]

10. Ciardelli, G.; Corsi, L.; Marussi, M. Membrane separation for wastewater reuse in the textile industry. Resour. Conserv. Recycl. 2001, 31, 109-113. [CrossRef]

11. Slokar, Y.M.; Marechal, A.M.L. Methods of Decoloration of Textile Wastewaters. Dyes Pigments 1998, 37, 335-356. [CrossRef]

12. De Gisi, S.; Lofrano, G.; Grassi, M.; Notarnicola, M. Characteristics and adsorption capacities of low-cost sorbents for wastewater treatment: A review. Sustain. Mater. Technol. 2016, 9, 10-40. [CrossRef]

13. Ali, I.; Asim, M.; Khan, T.A. Low cost adsorbents for the removal of organic pollutants from wastewater. J. Environ. Manag. 2012, 113, 170-183. [CrossRef] [PubMed]

14. Uddin, M.T.; Rahman, M.A.; Rukanuzzaman, M.; Islam, M.A. A potential low cost adsorbent for the removal of cationic dyes from aqueous solutions. Appl. Water Sci. 2017, 7, 2831-2842. [CrossRef]

15. Pathania, D.; Sharma, S.; Singh, P. Removal of methylene blue by adsorption onto activated carbon developed from Ficus carica bast. Arab. J. Chem. 2017, 10, S1445-S1451. [CrossRef]

16. Khodaie, M.; Ghasemi, N.; Moradi, B.; Rahimi, M. Removal of Methylene Blue from Wastewater by Adsorption onto $\mathrm{ZnCl}_{2}$ Activated Corn Husk Carbon Equilibrium Studies. J. Chem. 2013, 2013, 383985. [CrossRef]

17. EL-Mekkawi, D.M.; Ibrahim, F.A.; Selim, M.M. Removal of methylene blue from water using zeolites prepared from Egyptian kaolins collected from different sources. J. Environ. Chem. Eng. 2016, 4, 1417-1422. [CrossRef]

18. Song, G.; Shen, M.; Zhu, K.; Li, G. Adsorptive Removal of Methylene Blue by Mn-Modified Tourmaline. Nat. Environ. Pollut. Technol. 2018, 17, 243-247.

19. Yang, J.; Jing, R.; Wang, P.; Liang, D.; Huang, H.; Xia, C.; Zhang, Q.; Liu, A.; Meng, Z.; Liu, Y. Black phosphorus nanosheets and ZnAl-LDH nanocomposite as environmental-friendly photocatalysts for the degradation of Methylene blue under visible light irradiation. Appl. Clay Sci. 2021, 200, 105902. [CrossRef]

20. Rajendran, S.; Inwati, G.K.; Yadav, V.K.; Choudhary, N.; Solanki, M.B.; Abdellattif, M.H.; Yadav, K.K.; Gupta, N.; Islam, S.; Jeon, B.-H. Enriched Catalytic Activity of $\mathrm{TiO}_{2}$ Nanoparticles Supported by Activated Carbon for Noxious Pollutant Elimination. Nanomaterials 2021, 11, 2808. [CrossRef]

21. Zuorro, A.; Maffei, G.; Lavecchia, R. Kinetic modeling of azo dye adsorption on non-living cells of Nannochloropsis oceanica. J. Environ. Chem. Eng. 2017, 5, 4121-4127. [CrossRef]

22. Mouni, L.; Belkhiri, L.; Bollinger, J.C.; Bouzaza, A.; Assadi, A.; Tirri, A.; Dahmoune, F.; Madani, K.; Remini, H. Removal of Methylene Blue from aqueous solutions by adsorption on Kaolin: Kinetic and equilibrium studies. Appl. Clay Sci. 2018, 153, 38-45. [CrossRef]

23. Jourvand, M.; Shams Khorramabadi, G.; Omidi Khaniabadi, Y.; Godini, H.; Nourmoradi, H. Removal of methylene blue from aqueous solutions using modified clay. J. Basic Res. Med. Sci. 2015, 2, 32-41.

24. Sarasini, F.; Tirillò, J.; Zuorro, A.; Maffei, G.; Lavecchia, R.; Puglia, D.; Dominici, F.; Luzi, F.; Valente, T.; Torre, L. Recycling coffee silverskin in sustainable composites based on a poly (butylene adipate-co-terephthalate)/poly (3-hydroxybutyrate-co-3hydroxyvalerate) matrix. Ind. Crop. Prod. 2018, 118, 311-320. [CrossRef]

25. Srinivasan, R. Advances in application of natural clay and its composites in removal of biological, organic, and inorganic contaminants from drinking water. Adv. Mater. Sci. Eng. 2011, 2011, 872531. [CrossRef]

26. Feddal, I.; Ramdani, A.; Taleb, S.; Gaigneaux, E.M.; Batis, N.; Ghaffour, N. Adsorption capacity of methylene blue, an organic pollutant, by montmorillonite clay. Desalination Water Treat. 2014, 52, 2654-2661. [CrossRef]

27. Jain, A.; Ahmad, F.; Gola, D.; Malik, A.; Chauhan, N.; Dey, P.; Tyagi, P.K. Multi dye degradation and antibacterial potential of Papaya leaf derived silver nanoparticles. Environ. Nanotechnol. Monit. Manag. 2020, 14, 100337. [CrossRef] 
28. Ahmad, M.B.; Shameli, K.; Darroudi, M.; Yunus, W.M.; Ibrahim, N.A. Synthesis and characterization of silver/clay nanocomposites by chemical reduction method. Am. J. Appl. Sci. 2009, 6, 1909. [CrossRef]

29. Shameli, K.; Ahmad, M.B.; Yunus, W.M.Z.W.; Ibrahim, N.A.; Gharayebi, Y.; Sedaghat, S. Synthesis of silver/montmorillonite nanocomposites using $\gamma$-irradiation. Int. J. Nanomed. 2010, 5, 1067. [CrossRef]

30. Sedaghat, S. Green biosynthesis of silver-montmorillonite nanocomposite using water extract of Ziziphora tenuior L. Curr. Nanosci. 2016, 12, 79-82. [CrossRef]

31. Moradi, F.; Sedaghat, S.; Arab-Salmanabadi, S.; Moradi, O. Biosynthesis of silver-montmorillonite nanocomposites using Ocimum basilicum and Teucrium polium; a comparative study. Mater. Res. Express 2019, 6, 125008. [CrossRef]

32. Ghiassi, S.; Sedaghat, S.; Mokhtary, M.; Kefayati, H. Plant-mediated bio-synthesis of silver-montmorillonite nanocomposite and antibacterial effects on gram-positive and-negative bacteria. J. Nan. Chem. 2018, 8, 353-357. [CrossRef]

33. Zuorro, A.; Iannone, A.; Natali, S.; Lavecchia, R. Green synthesis of silver nanoparticles using bilberry and red currant waste extracts. Processes 2019, 7, 193. [CrossRef]

34. Saha, J.; Begum, A.; Mukherjee, A.; Kumar, S. A novel green synthesis of silver nanoparticles and their catalytic action in reduction of Methylene Blue dye. Sustain. Environ. Res. 2017, 27, 245-250. [CrossRef]

35. Benjumea, D.M.; Gómez-Betancur, I.C.; Vásquez, J.; Alzate, F.; García-Silva, A.; Fontenla, J.A. Neuropharmacological effects of the ethanolic extract of Sida acuta. Rev. Bras. Farmacogn. 2016, 26, 209-215. [CrossRef]

36. Uysal, S.; Gevrenova, R.; Sinan, K.I.; Bayarslan, A.U.; Altunoglu, Y.C.; Zheleva-Dimitrova, D.; Ak, G.; Baloglu, M.C.; Etienne, O.K.; Lobine, D.; et al. New perspectives into the chemical characterization of Sida acuta Burm. f. extracts with respect to its anti-cancer, antioxidant and enzyme inhibitory effects. Process Biochem. 2021, 105, 91-101. [CrossRef]

37. Gashti, M.P.; Almasian, A. Synthesizing tertiary silver/silica/kaolinite nanocomposite using photo-reduction method: Characterization of morphology and electromagnetic properties. Compos. Part B Eng. 2012, 43, 3374-3383. [CrossRef]

38. Karickhoff, S.W.; Bailey, G.W. Optical absorption spectra of clay minerals. Clays Clay Miner. 1973, 21, 59-70. [CrossRef]

39. Wanyika, H.; Maina, E.; Gachanja, A.; Marika, D. Instrumental Characterization of Montmorillonite Clays by X-Ray Fluorescence Spectroscopy, Fourier Transform Infrared Spectroscopy, X-ray Diffraction and Uv/Visible Spectrophotometry. J. Agric. Sci. Technol. 2016, 17, 224-239.

40. Farmer, V.C. The Layer Silicates. In The Infrared Spectra of Minerals; Farmer, V.C., Ed.; Mineralogical Society: London, UK, 1974; pp. 331-363.

41. Gao, Y.; Choudhury, N.R.; Dutta, N.K. Systematic study of interfacial interactions between clays and an ionomer. J. Appl. Polym. Sci. 2010, 117, 3395-3405. [CrossRef]

42. Sing, K.S.W.; Williams, R.T. Pysisorption hysteresis loop and the characterization of nanoporous material. Rev. AST 2005, $22,773$. [CrossRef]

43. Almeida, C.A.P.; Debacher, N.A.; Downs, A.J.; Cottet, L.; Mello, C.A.D. Removal of methylene blue from colored effluents by adsorption on montmorillonite clay. J. Collö̈d Interface Sci. 2009, 332, 46-53. [CrossRef]

44. Khan, M.I. Adsorption of methylene blue onto natural Saudi Red Clay: Isotherms, kinetics and thermodynamic studies. Mater. Res. Express 2020, 7, 055507. [CrossRef]

45. Uyanika, O.L.; Bektasb, N.; Uyanikb, N. Adsorption Characteristics of Methylene Blue on Some Special Modified Clays. Int. J. Appl. Eng. Res. 2018, 13, 11112-11122.

46. Yadav, V.K.; Yadav, K.K.; Cabral-Pinto, M.M.S.; Choudhary, N.; Gnanamoorthy, G.; Tirth, V.; Prasad, S.; Khan, A.H.; Islam, S.; Khan, N.A. The Processing of Calcium Rich Agricultural and Industrial Waste for Recovery of Calcium Carbonate and Calcium Oxide and Their Application for Environmental Cleanup: A Review. Appl. Sci. 2021, 11, 4212. [CrossRef]

47. Virendra Kumar, Y.; Nisha, C.; Samreen Heena, K.; Parth, M.; Gajendra Kumar, I.; Suriyaprabha, R.; Raman Kumar, R. Synthesis and Characterisation of Nano-Biosorbents and Their Applications for Waste Water Treatment. In Handbook of Research on Emerging Developments and Environmental Impacts of Ecological Chemistry; Gheorghe, D., Ashok, V., Eds.; IGI Global: Hershey, PA, USA, 2020; pp. 252-290. [CrossRef]

48. Inwati, G.K.; Rao, Y.; Singh, M. Thermodynamically induced in Situ and Tunable Cu Plasmonic Behaviour. Sci. Rep. 2018, 8, 3006. [CrossRef] [PubMed] 